\title{
horticultura
brasileira
}

ECHER, MM; DALASTRA, GM; HACHMANN, TL; GUIMARÃES, VF; FIAMETTI, MS. 2016. Desempenho de cultivares de berinjela em plantio direto e convencional. Horticultura Brasileira 34: 239-243. DOI - http://dx.doi.org/10.1590/S0102-053620160000200014

\section{Desempenho de cultivares de berinjela em plantio direto e convencional}

\author{
Márcia M Echer; Graciela M Dalastra; Tiago L Hachmann; Vandeir F Guimarães; Mayara S Fiametti \\ Universidade Estadual Oeste do Paraná (UNIOESTE), Marechal Cândido Rondon-PR, Brasil; mmecher@bol.com.br; gradalastra@, \\ hotmail.com; tiagohach@gmail.com; vandeirfg@yahoo.com.br; mayarafiametti@hotmail.com
}

\section{RESUMO}

O objetivo deste trabalho foi avaliar a influência do sistema plantio direto e convencional, sob aveia preta (Avena strigosa), na qualidade e produtividade da berinjela. $\mathrm{O}$ experimento foi conduzido na Universidade Estadual do Oeste do Paraná, Marechal Cândido Rondon-PR. O delineamento experimental utilizado foi de blocos ao acaso em esquema fatorial $6 \times 2$, com quatro repetições. Os tratamentos foram compostos de seis cultivares de berinjela (Nápoli, F 2000, Zebrita, Redonda Rosa, Roma e Napolitana) e dois sistemas de manejo de solo (plantio direto sobre palhada de aveia e preparo convencional com incorporação da palhada). $\mathrm{O}$ experimento foi realizado em duas etapas. A primeira, referente à semeadura da aveia, foi realizada em junho de 2008, sendo que a dessecação ocorreu 105 dias após a semeadura, quando foi também avaliada a biomassa seca. A segunda etapa foi o transplante e condução das mudas de berinjela na área. A colheita iniciou 60 dias após o transplante. Os frutos foram classificados em "normais", "com defeito leve" e "com defeito grave". Em todas as classes de frutos foram avaliados o diâmetro e comprimento médio dos frutos, a massa média de um fruto e a massa de frutos por planta, além de calculada a produtividade. As cultivares Nápoli, F 2000 e Zebrita foram as mais produtivas, independente do sistema de cultivo utilizado. O sistema plantio direto proporcionou maior produtividade para as cultivares de berinjela em estudo; em média as plantas produziram $700 \mathrm{~g}$ de frutos a mais, em relação ao sistema convencional. Além disso, no sistema de plantio direto, o número de frutos com defeito grave foi $2,34 \%$ menor, que no sistema convencional.

\begin{abstract}
Production of eggplant cultivars depending on soil tillage systems

This work evaluated the influence of a no-tillage system on quality and productivity of eggplant following oat (Avena strigosa) cultivation. The experiment was carried out in Marechal Cândido Rondon, Paraná State, Brazil. Randomized blocks in factorial $6 \times 2$ design was used with four replications. Treatments were six eggplant cultivars (Nápoli, F 2000, Zebrita, Redonda Rosa, Roma and Napolitana), and two soil tillage systems (no-tillage on oat straw and conventional tillage with incorporation of straw). Oat sowing was held in June 2008, and desiccation occurred 105 days after, dry biomass being evaluated. Then, transplanting and conduction of eggplant seedlings were carried out. Harvest begun 60 days after transplantation. Fruits were classified as "normal", "with slight defects" and "severe defect". Regarding fruits, we evaluated diameter, average length, average mass, mass of fruits per plant and yield on all fruit classes. The cvs. Nápoli, F 2000 and Zebrita were the most productive ones, regardless the cropping system used. The no-tillage system provided a higher productivity for the studied cultivars. On average, plants in this system produced additional $700 \mathrm{~g}$ of fruits when compared to the conventional system. Moreover, under no-tillage, the number of fruits with severe defect was $2.34 \%$ lower than in the conventional system.
\end{abstract}

Palavras-chave: Solanum melongena, manejo do solo, produtividade, qualidade.

Keywords: Solanum melongena, soil management, yield quality.

(Recebido para publicação em 16 de novembro de 2014; aceito em 28 de agosto de 2015) (Received on November 16, 2014; accepted on August 28, 2015)

A tualmente a agricultura vem sofrendo alterações devido à necessidade de um novo modelo de produção, que seja menos prejudicial ao ecossistema e de maior sustentabilidade. Desta forma, justifica-se a adoção de meios alternativos de produção que resultem em menor agressão ao agroecossistema, sem diminuir a produtividade e a qualidade dos frutos.

O sistema plantio direto na palha surge como uma alternativa para mi- nimizar os impactos causados pelo atual modelo de produção de hortaliças. Dentre os benefícios deste sistema está a redução da erosão laminar e da lixiviação de nutrientes. Essa prática pode contribuir também com o aumento de matéria orgânica do solo, melhoria de sua estrutura, aumento da infiltração e retenção de água, além de reduzir a amplitude térmica e a incidência de plantas daninhas (Boer et al., 2008).

Esse sistema também respeita os três requisitos mínimos: não revolvimento do solo, rotação de culturas e uso de culturas de cobertura para formação de palhada, associados ao manejo integrado de pragas, doenças e plantas daninhas (Embrapa, 2003).

No cultivo de hortaliças, devido ao ciclo muito rápido, o solo é utilizado de forma intensiva. Desta forma o plantio direto tem como principal objetivo reverter o quadro de degradação física, química e biológica desses solos. Po- 
rém, o plantio de hortaliças no sistema plantio direto é quase inexpressivo, quando comparado com o progresso das grandes culturas, onde já é uma pratica consolidada há mais de duas décadas (Madeira, 2009). Para a escolha das plantas de cobertura a serem utilizadas nos sistemas de produção de hortaliças, visando à formação de palhada, deve-se considerar as que melhor se adaptam à região em questão.

Oliveira et al. (2005), ao cultivar repolho em sistema plantio direto, verificaram aumento de produtividade. Melo et al. (2010), para a produção de brócolis, não verificaram diferenças nos níveis de produtividade para os sistemas plantio direto e convencional. Sendo assim, os autores relatam que é recomendável sua adoção, considerando-se os benefícios proporcionados pelo sistema plantio direto.

Castro et al. (2004) concluíram que o cultivo de berinjela em plantio direto é possível de ser realizado obtendo-se produção satisfatória, pois o fornecimento de nutrientes, principalmente o nitrogênio, através do plantio de leguminosas, pode suprir praticamente toda a quantidade de nutrientes exportada pela cultura.

Segundo Factor et al. (2010), o plantio direto, quando conduzido adequadamente, com emprego de plantas de cobertura adaptadas regionalmente e em rotação com cultivos comerciais, permite maior diversificação de espécies e menor incidência de pragas e doenças. Marouelli et al. (2006) verificaram que, com a presença da palhada sobre a superfície do solo no sistema plantio direto, a produtividade dos frutos do tomateiro foi maior, além de reduzir a incidência de frutos sem valor comercial.

O objetivo deste trabalho foi indicar qual a cultivar de berinjela que melhor se adapta ao sistema plantio direto e convencional.

\section{MATERIAL E MÉTODOS}

O experimento foi conduzido no período de junho de 2008 a abril de 2009 na Estação Experimental Prof. Dr. Antônio Carlos dos Santos Pessoa, pertencente à Universidade Estadual do Oeste do Paraná, Marechal Cândido Rondon-PR ( $24^{\circ} 33^{\prime} \mathrm{S}, 54^{\circ} 31^{\prime} \mathrm{O}$, altitude $420 \mathrm{~m}$ ). O solo é classificado como Latossolo Vermelho Eutroférrico de textura argilosa (Embrapa, 2006).

Para a caracterização química do solo foram realizadas coletas em toda a área experimental, na profundidade 0 a $20 \mathrm{~cm}$, cujos resultados encontrados foram: $\mathrm{pH}\left(\mathrm{CaCl}_{2}\right)=5,62$; Matéria Orgânica $=27,00 \mathrm{~g} / \mathrm{dm}^{3} ; \mathrm{P}=44,02 \mathrm{mg} / \mathrm{dm}^{3}$; $\mathrm{K}=0,68 \mathrm{cmol}_{\mathrm{c}} \mathrm{dm}^{3} ; \mathrm{Ca}^{2+}=6,49 \mathrm{cmol}_{\mathrm{c}}$ $\mathrm{dm}^{3} ; \mathrm{Mg}^{2+}=1,97 \mathrm{cmol}_{\mathrm{c}} \mathrm{dm}^{3} ; \mathrm{Al}^{3+}=0 \%$; $\mathrm{SB}=9,14$ e $\mathrm{V}(\%)=68,40$.

O delineamento experimental utilizado foi de blocos ao acaso em esquema fatorial $6 \times 2$, com quatro repetições. Os tratamentos constaram de seis cultivares de berinjela (Nápoli, F 2000, Zebrita, Redonda Rosa, Roma e Napolitana) e dois sistemas de manejo do solo (plantio direto na palhada de aveia e plantio convencional onde a aveia foi incorporada).

Este experimento foi realizado em duas etapas, sendo que a primeira etapa foi a semeadura e manejo da aveia preta (Avena strigosa) e a segunda etapa a implantação e condução do cultivo de berinjela.

A semeadura da aveia-preta foi realizada de forma manual, em toda a área do experimento. Após a distribuição das sementes, as mesmas foram incorporadas no solo, a cinco centímetros de profundidade. A dessecação da aveia foi realizada no final do mês de setembro de 2008, quando a mesma encontrava-se em plena floração. Neste momento foram coletadas amostras da parte aérea para determinação da matéria seca. A amostragem foi realizada ao acaso, em oito pontos da área, com auxílio de uma moldura de $1 \mathrm{~m}^{2}$. Foi coletado todo o material vegetal presente dentro da moldura. Essas amostras foram acondicionadas em sacos de papel e em seguida colocadas para secar em estufa de circulação forçada de ar a $65^{\circ} \mathrm{C}$, até atingir massa constante, para determinação da massa seca acumulada.

O preparo do solo no plantio convencional foi constituído de aração e gradagem, incorporando a aveia dessecada ao solo. No sistema plantio direto o revolvimento do solo foi mínimo, restrito às covas.

A segunda etapa do experimento iniciou-se com o transplantio das mudas de berinjela. As mudas foram produzidas em bandejas de poliestireno expandido de 128 células, contendo substrato comercial. A semeadura foi realizada em setembro de 2008, colocando-se uma semente por célula. As bandejas foram mantidas em casa de vegetação até o momento do transplante. $\mathrm{O}$ transplante ocorreu aos 46 dias após a semeadura, quando as mudas apresentavam quatro folhas definitivas.

As parcelas experimentais foram constituídas de oito plantas, sendo que os frutos avaliados pertenciam às quatro plantas centrais da parcela. $\mathrm{O}$ espaçamento entre plantas foi de $70 \mathrm{~cm}$, e entre linhas de $1,30 \mathrm{~m}$.

A adubação da cultura foi realizada de acordo com as análises de solo e com as recomendações de Trani et al. (1997), sendo a adubação de plantio incorporada à cova e a de cobertura distribuída próximo à planta, com incorporação superficial. O controle fitossanitário e os demais tratos culturais foram realizados conforme a necessidade da cultura.

A colheita dos frutos estendeu-se dos 60 aos 159 dias após o transplantio (DAT). O ponto de colheita foi determinado visualmente, dependendo da cultivar, do tipo e da coloração do fruto. De maneira geral, os frutos foram colhidos quando apresentavam coloração brilhante, polpa macia e firme. Depois de colhidos, os frutos foram classificados em "normais", com "defeito leve" e com "defeito grave", conforme a cartilha da Companhia de Entrepostos e Armazéns Gerais de São Paulo (CEAGESP, 2000). Os frutos foram avaliados quanto ao diâmetro médio (DMF), comprimento médio (CMF), massa média do fruto (MMF) e massa de frutos por planta $(\mathrm{kg})$. Calculou-se também a produtividade das plantas, expressa em t/ha.

Depois de tabulados, os dados foram submetidos à análise de variância e as médias comparadas pelo teste de Tukey ( $\mathrm{p} \leq 0,05)$. Utilizou-se o programa estatístico SAEG, versão para Windows da UFV.

\section{RESULTADOS E DISCUSSÃO}

Neste experimento obteve-se uma 
produção de $4,43 \mathrm{t} /$ ha de massa seca da parte aérea de plantas de aveia. Segundo Alvarenga et al. (2001), esse valor não atinge a quantidade de massa seca considerada suficiente para uma boa proteção do solo. Estes autores consideram que a quantidade mínima ideal de massa seca para que se mantenha a adequada cobertura do solo é de 6,00 t/ha. Apesar da baixa quantidade de massa seca acumulada, esse resultado é semelhante aos obtidos por Canto et al. (1997) que observaram produção total de matéria seca de aveia preta de 4,54 t/ha e por Cecato et al. (1998) que obtiveram produção de 4,20 t/ha

Não houve interação significativa entre as cultivares estudadas e os dois sistemas de cultivo, mas houve diferença entre os sistemas e as cultivares. As características produtivas de cultivares de berinjela e do sistema de cultivo são apresentadas separadamente (Tabelas 1 e 2).

Existem diferenças, no formato dos frutos de berinjela, entre as cultivares estudadas (Tabela 1). As cultivares Zebrita e Redonda Rosa apresentam formato mais arredondado, destacando-se o menor comprimento dos frutos, enquanto as cultivares Nápoli, F 2000, Roma e Napolitana, apresentam maior comprimento dos frutos em relação ao diâmetro. A cultivar Zebrita apresentou o maior diâmetro de frutos enquanto que as cultivares Nápoli, Roma e Napolitana, se destacaram pelo maior comprimento dos frutos. Estas respostas são inerentes às características genéticas dos materiais testados, destacando-se que estas se mantêm nos dois sistemas de cultivo, confirmado pela ausência de interação entre os fatores em estudo.

Ao avaliar a massa média de frutos, conforme Tabela 1, verifica-se grande variabilidade entre os materiais testados, destacando-se as cultivares Zebrita e Redonda Rosa, que apresentaram massa média de frutos de 80,4 e 81,6 g, respectivamente, mesmo não diferindo do híbrido F 2000, com 74,5 g. As cultivares que apresentaram frutos com menor massa foram Roma e Napolitana, com 53,8 e 60,0 g por fruto, respectivamente.

Quanto à produção de frutos por planta destaca-se a cultivar F 2000, que foi mais produtiva que as cultivares

Figura 1. Produtividade de seis cultivares de berinjela e em dois sistemas de cultivo. Médias seguidas da mesma letra não diferem pelo teste de Tukey $(\mathrm{p} \leq 0,05)$ \{productivity of six eggplant cultivars in two cropping systems. Means followed by the same letter in the column do not differ by Tukey test $(\mathrm{p} \leq 0.05)\}$. Marechal Cândido Rondon, UNIOESTE, 2009.

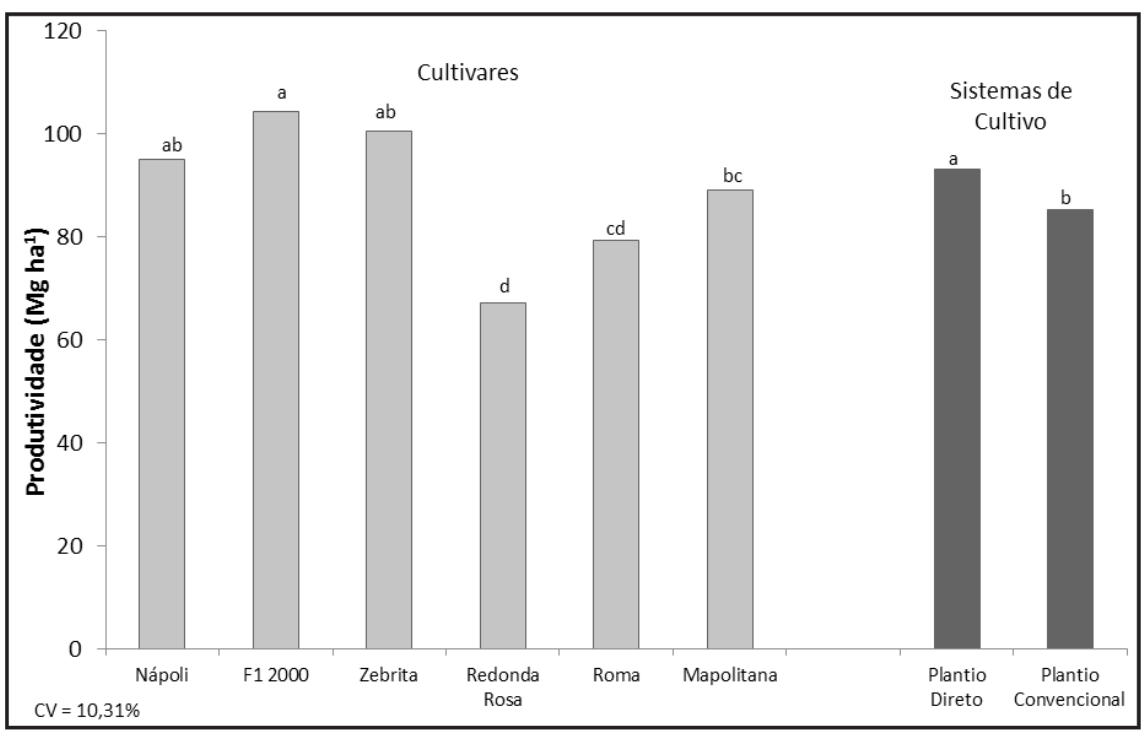

Figura 2. Percentagem de frutos normais, com defeitos leves e com defeitos graves, em plantio direto na palha e em sistema de plantio convencional. Médias seguidas da mesma letra não diferem pelo teste de Tukey $(\mathrm{p} \leq 0,05)$ \{percentage of normal fruits with small defects and severe defects on no-tillage and conventional tillage system. Means followed by the same letter in the column do not differ by Tukey test $(\mathrm{p} \leq 0.05)\}$. Marechal Cândido Rondon, UNIOESTE, 2009.

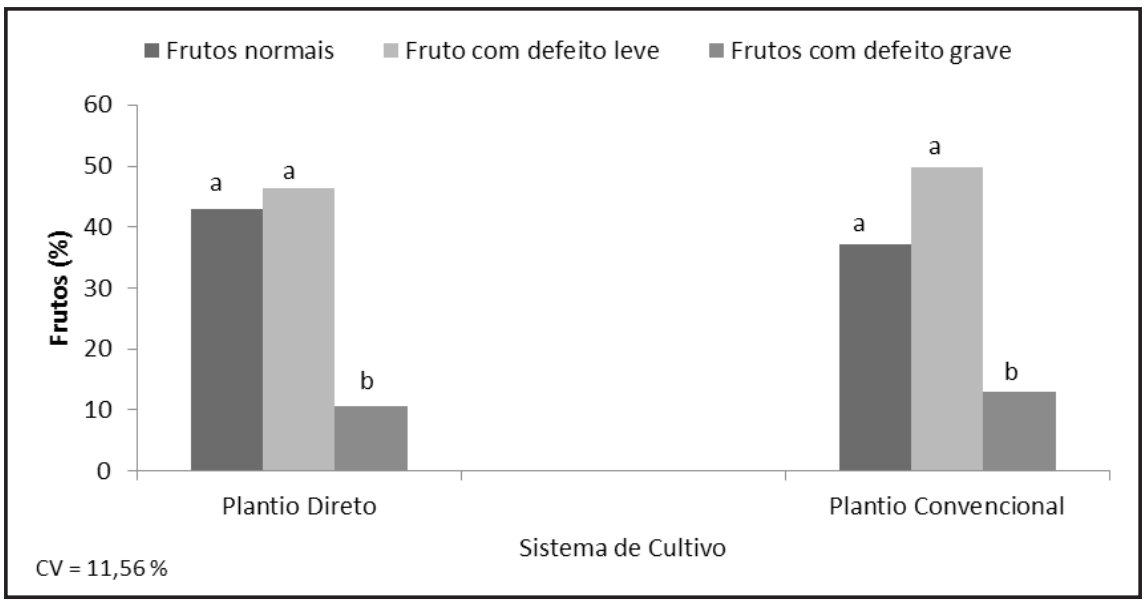

Redonda Rosa, Roma e Napolitana, mesmo não diferindo significativamente das cultivares Nápoli e Zebrita. A cultivar Redonda Rosa mostrou-se menos produtiva quando comparada às demais, com aproximadamente $6 \mathrm{~kg}$ de frutos por planta, enquanto a cultivar F 2000 produziu em média $9,5 \mathrm{~kg}$ por planta.

Os valores de produção obtidos no presente trabalho superam os de Lima et al. (2012) com a cultivar Ciça em plantio direto sob diferentes lâminas de irrigação (6.760 $\mathrm{g}$ de fruto por planta) e
Bilibio et al. (2010), testando o efeito de diferentes tensões de água no solo (1,72 kg por planta, com a cultivar Nápoli).

Resultados de literatura mostram que geralmente não ocorrem incrementos em produção no início da implantação do sistema plantio direto, mas sim após esse sistema de cultivo estar consolidado. Contudo, neste estudo, foi possível observar aumento na produção logo no primeiro ciclo de cultivo (Tabela 2).

Nespoli et al. (2013) concluíram 
que o plantio direto de brócolis tipo inflorescência única não influenciou os componentes de rendimento da cultura (produção por planta e diâmetro da inflorescência); sendo assim, a produtividade não foi alterada quando comparada com o plantio convencional.

Esse melhor desempenho produtivo da berinjela no plantio direto em relação ao plantio convencional, no presente trabalho, pode estar relacionado com o acúmulo de carbono, à diminuição da temperatura do solo e à melhor eficiência no uso da água (Silva et al., 2006).

Esta resposta positiva no sistema plantio direto pode estar também associada às características da planta de berinjela, que é uma planta rústica e com sistema radicular bastante agressivo. Desta forma as condições de solo criadas pelo plantio direto em detrimento ao sistema convencional, onde a matéria orgânica (palhada de aveia) foi incorporada no solo durante as operações de preparo, favorece o desenvolvimento radicular e consequentemente da espécie.

Os resultados obtidos no presente trabalho indicam o sistema plantio direto como mais promissor nos próximos anos de cultivo de hortaliças na área. Melo et al. (2010) recomendam a adoção do plantio direto, considerando os benefícios proporcionados por este sistema de cultivo, principalmente para a qualidade do solo, haja visto que as produtividades obtidas no cultivo do brócolis nesse sistema foram semelhantes às encontradas no preparo convencional.

Os dados de produtividade das seis cultivares de berinjela (Figura 1) vêm corroborar com os resultados já apresentados e discutidos anteriormente. Vale destacar o maior potencial produtivo das cultivares Nápoli, F 2000 e Zebrita, com produtividades aproximadas de $100 \mathrm{t} / \mathrm{ha}$ de frutos, enquanto a cultivar Redonda Rosa foi estatisticamente inferior, produzindo aproximadamente $70 \mathrm{t} / \mathrm{ha}$. Essa menor produtividade da cultivar Redonda Rosa, possivelmente, ocorre em decorrência da sua maior suscetibilidade ao ataque de pragas, principalmente ácaros, acarretando em prejuízos na produtividade final.

A produtividade foi maior no cultivo com plantio direto em relação ao convencional (Figura 1). Esta maior

Tabela 1. Dados médios obtidos nos dois sistemas de cultivo: Diâmetro médio de frutos (DMF), comprimento médio de frutos (CMF), massa média de frutos (MMF) e massa de frutos por planta (MFP) de seis cultivares de berinjela \{average fruit diameter (DMF), average length of fruits (CMF), average mass of fruits (MMF) and mass of fruits per plant (MFP) of six cultivars of eggplant\}. Marechal Cândido Rondon, UNIOESTE, 2009.

\begin{tabular}{lcccc}
\hline Cultivares & DMF (cm) & CMF (cm) & MMF (g) & MFP (kg) \\
\hline Nápoli & $4,81 \mathrm{ab}$ & $10,96 \mathrm{a}$ & $70,23 \mathrm{~b}$ & $8,66 \mathrm{ab}$ \\
F 2000 & $4,30 \mathrm{bc}$ & $10,29 \mathrm{ab}$ & $74,50 \mathrm{ab}$ & $9,49 \mathrm{a}$ \\
Zebrita & $4,98 \mathrm{a}$ & $8,99 \mathrm{~b}$ & $80,40 \mathrm{a}$ & $9,14 \mathrm{ab}$ \\
Redonda Rosa & $4,03 \mathrm{c}$ & $4,49 \mathrm{c}$ & $81,57 \mathrm{a}$ & $6,11 \mathrm{~d}$ \\
Roma & $4,07 \mathrm{c}$ & $11,39 \mathrm{a}$ & $53,77 \mathrm{c}$ & $7,22 \mathrm{~cd}$ \\
Napolitana & $4,32 \mathrm{bc}$ & $11,41 \mathrm{a}$ & $60,04 \mathrm{c}$ & $8,11 \mathrm{bc}$ \\
\hline CV (\%) & 9,47 & 10,53 & 7,07 & 10,31 \\
\hline
\end{tabular}

*Médias seguidas da mesma letra na coluna não diferem pelo teste de Tukey $(\mathrm{p} \leq 0,05)$ \{means followed by the same letter in the column do not differ by Tukey test $(\mathrm{p} \leq 0.05)\}$.

Tabela 2. Diâmetro médio de frutos (DMF), comprimento médio de frutos (CMF), massa média de um fruto (MMF) e massa de frutos por planta (MFP) em dois sistemas de cultivo \{average fruit diameter (DMF), average length of fruits (CMF), average mass of fruit (MMF) and mass of fruits per plant (MFP) in two cropping systems). Marechal Cândido Rondon, UNIOESTE, 2009.

\begin{tabular}{lcccc}
\hline $\begin{array}{l}\text { Sistema de cultivo } \\
\text { ou plantio }\end{array}$ & DMF (cm) & CMF (cm) & MMF (g) & MFP (kg) \\
\hline Plantio direto & $4,48 \mathrm{a}$ & $9,99 \mathrm{a}$ & $70,37 \mathrm{a}$ & $8,47 \mathrm{a}$ \\
Plantio convencional & $4,36 \mathrm{a}$ & $9,19 \mathrm{~b}$ & $69,81 \mathrm{a}$ & $7,77 \mathrm{~b}$ \\
\hline CV (\%) & 9,47 & 10,53 & 7,07 & 10,31 \\
\hline
\end{tabular}

*Médias seguidas da mesma letra na coluna não diferem pelo teste de Tukey $(\mathrm{p} \leq 0,05)$ \{means followed by the same letter in the column do not differ by Tukey test $(\mathrm{p} \leq 0.05)\}$.

produtividade pode estar correlacionada com a melhoria das propriedades físicas, químicas e biológicas do solo, tais como menor temperatura, umidade do solo mais adequada, menor competição com plantas daninhas, refletindo positivamente em ganho de produtividade.

Resultados semelhantes foram obtidos por Pott \& Feltrin (2008) que observaram maior produção no cultivo de tomate cereja em sistema plantio direto. Esses autores notaram que a adição de matéria seca ao solo resultou em aumentos da produtividade do número de frutos por planta e da massa média de frutos.

Ao avaliar o desempenho agronômico do coentro em sistema plantio direto com diferentes tipos de cobertura viva e palhada, Tavella et al. (2010) verificaram que o plantio direto na resteva morta proporcionou melhor desempenho agronômico do coentro.

Na Figura 2 são apresentadas as porcentagens de frutos normais, com defeitos leves e com defeitos graves nos dois sistemas de manejo do solo. Verifica-se que para ambos os sistemas, não houve diferença significativa entre frutos normais e com defeitos leves, ocorrendo diferença somente em relação à percentagem de frutos com defeito grave.

Diante do desempenho das cultivares de berinjela, pode-se concluir que as cultivares Nápoli, F 2000 e Zebrita são as mais produtivas para a região. $\mathrm{O}$ sistema plantio direto proporcionou produtividade superior para as cultivares de berinjela em estudo em relação ao sistema convencional. Portanto, é recomendada a adoção desse sistema, haja visto outros benefícios que o mesmo traz para a agricultura e ambiente de uma maneira geral.

\section{REFERÊNCIAS}

ALVARENGA, RC; CABEZAS, WL; CRUZ, JC; SANTANA, DP. 2001. Plantas para cobertura 
do solo para sistema de plantio direto. Informe Agropecuário 22: 25-36.

BILIBIO, C; CARVALHO, JA; MARTINS, M; REZENDE, FC; FREITAS, EA; GOMES, LAA. 2010. Desenvolvimento vegetativo e produtivo da berinjela submetida a diferentes tensões de água no solo. Revista Brasileira de Engenharia Agrícola e Ambiental 14: 730-735.

BLOER, AC; ASSIS, RL; SILVA, GP; BRAZ, AJBP; BARROSO, ALL; CARGNELUTTI FILHO, A; PIRES, FR. 2008. Biomassa, decomposição e cobertura do solo ocasionada por resíduos culturais de três espécies vegetais na região Centro Oeste do Brasil. Revista Brasileira de Ciênica do Solo, Viçosa 32: 843- 851.

CANTO, MW; RESTLE, J; QUADROS, FLF; LUPATINI, GC; MORAES, AG. 1997. Produção animal em pastagens de Aveia (Avena strigosa) adubada com nitrogênio ou em mistura com ervilhaca (Vicia sativa). Revista Brasileira Zootecnia 26: 396-402.

CASTRO, CM; ALVES, BJR; ALMEIDA, DL; RIBEIRO, RLD. 2004. Adubação verde como fonte de nitrogênio para a cultura da berinjela em sistema orgânico. Pesquisa Agropecuária Brasileira 39: 779-785.

CEAGESP. 2000. Classificação da berinjela. São Paulo: CEAGESP. (Folder). Disponível em: http://www.hortibrasil.org.br/jnw/ classificacao/berinjela/arquivos/norma.html

CECATO, U; RÊGO, FCA; GOMES, JAN; CANTO, MW; JOBIM, CC; CONEGLIAN,
S; MOREIRA, FB. 1998. Avaliação de cultivares e linhagens de aveia (Avena spp.). Acta Scientiarum 20: 347-354.

EMBRAPA. 2003 Plataforma: Plantio direto (www.embrapa.br/plantiodireto/). Acessado em 24/03/2009.

EMBRAPA, Centro Nacional de Pesquisa em Solos. 2006. Sistema brasileiro de classificação de solos. Rio de Janeiro: Embrapa-Solos. 306p.

FACTOR, TL; LIMA, JRS; PURQUERIO, LFV; BREDA JÚNIOR, JM; CALORI, AHC. 2010. Produção de beterraba em plantio direto sob diferentes palhadas. In: CONGRESSO BRASILEIRO DE OLERICULTURA, $50^{\circ}$. Resumos... Guarapari: SOB (CD-Rom).

LIMA, ME; CARVALHO, DF; SOUZA, AP; ROCHA, HS; GUERRA, JGM. 2012. Desempenho do cultivo da berinjela em plantio direto submetida a diferentes lâminas de irrigação. Revista Brasileira de Engenharia Agrícola e Ambiental 16: 604-610.

MADEIRA, NR. 2009. Sistema de plantio direto chega às hortaliças. Revista Campo e Negócios 5: $18-23$.

MAROUELLI, WA; SILVA, HR; MADEIRA, NR. 2006. Uso de água e produção de tomateiro para processamento em sistema de plantio direto com palhada. Pesquisa Agropecuária Brasileira 41: 1399-1404.

MELO, RAC; MADEIRA, NR; PEIXOTO, JR. 2010. Cultivo de brócolos de inflorescência única no verão em plantio direto. Horticultura Brasileira 28: 23-28.
NESPOLI, A; NEVES, JF; JÚNIOR, SS; ARANTES, EM; NUNES, MCM. 2013. Cultivo de brócolis de inflorescência única sob diferentes coberturas de solo. Enciclopédia Biosfera 9: 917.

OLIVEIRA, FL; RIBAS, RGT; JUNQUEIRA, RM; PADOVAN, MP; GUERRA, JGM; ALMEIDA, DL; RIBEIRO, RLD. 2005. Desempenho do consórcio entre repolho e rabanete com pré-cultivo de crotalária, sob manejo orgânico. Horticultura Brasileira 32: 184-188.

POTT, CA; FELTRIN, DM. 2008. Adubação verde em tomateiro cultivado em sistema de agricultura orgânica. Revista do Setor de Ciências Agrárias e Ambientais 4: 220.

SILVA, VR; REICHERT, JM; REINERT, DJ. 2006. Variação na temperatura do solo em três sistemas de manejo na cultura do feijão. Revista Brasileira de Ciência do Solo 30: 391-399.

TAVELLA, LB; GALVÃO, RO; FERREIRA, RLF; NETO, SEA; NEGREIROS, JRS. 2010. Cultivo orgânico de coentro em plantio direto utilizando cobertura viva e morta adubado com composto. Revista Ciência Agronômica 41: 614-618.

TRANI, PE; PASSOS, FA; TAVARES, M; AZEVEDO FILHO, JA. In: RAIJ, VB; CANTARELLA, H; QUAGGIO,JA; FURLANI, AMC. 1997. Recomendação de adubação e calagem para o Estado de São Paulo. Campinas: Instituto Agronômico/ Fundação IAC. 174p. (Boletim Técnico, 100). 